Int. J. Dev. Biol. 49: 317-324 (2005)

doi: $10.1387 / \mathrm{ijdb} .041955 \mathrm{cf}$

\title{
Running after the clock
}

\author{
CATARINA FREITAS ${ }^{1}$, SOFIA RODRIGUES ${ }^{1,2}$, LEONOR SAÚDE ${ }^{1}$ and ISABEL PALMEIRIM*,1,2 \\ ${ }^{1}$ Instituto Gulbenkian de Ciência, Oeiras, Portugal and ${ }^{2}$ Life and Health Science Research Institute (ICVS), School of Health Sciences, \\ University of Minho, Braga, Portugal
}

\begin{abstract}
The way we currently understand vertebrate development is undoubtedly associated with the research undertaken at the "Institut d'Embryologie Cellulaire et Moléculaire" at Nogentsur-Marne during the last decades. Working in this Institute has been a privilege for many junior and senior researchers. Eight years ago, in this stimulating environment, an exciting observation followed by a series of revealing experiments gave rise to a novel field of research. This study provided evidence for the existence of a molecular clock underlying chick somite formation. In this review, we focus on the cascade of studies that have followed this discovery. Thus far, it has been demonstrated that the molecular clock is operating in several vertebrate models namely chick, mouse, zebrafish, frog and medaka, probably functioning to provide cells with multidimensional positional information. Loss and gain of function experiments and detailed gene promoter analyses have proved very useful in understanding how the clock machinery works. Recent data has also led to the fascinating hypothesis that the clock might not be an exclusive property of somitic cells, but rather a mechanism used by a wide range of embryonic tissues. Meanwhile, the clock “keeps ticking" and many questions are still waiting for an answer.
\end{abstract}

KEY WORDS: molecular clock, cycling gene, segmentation, somitogenesis, vertebrate embryo

Segmentation is an evolutionary successful feature that starts early during embryonic development with the formation of transient metameric structures called somites. Somites will give rise to the segmented structures in the vertebrate embryo such as vertebrae, intervertebral disks, ribs and skeletal muscles. These structures provide an efficient protection to the internal vital organs, while conferring a high degree of mobility to the adult body. Somites form as epithelial spheres in an anterior $(A)$ to posterior $(P)$ sequential manner, bilateral to the axial midline of the embryo. Each somite buds off periodically from the most anterior tip of the unsegmented mesenchymal paraxial mesoderm or presomitic mesoderm (PSM) (reviewed by Gossler and Hräbe de Angelis, 1998). For a given species, temporal periodicity of somite formation is so remarkably precise that it has retained the attention of embryologists for many decades. Several theoretical models have tried to explain the precision of somitogenesis. Many aspects of the cellular and molecular mechanisms underlying this process have been unveiled in the last years although many fundamental questions remain to be addressed.

\section{Somite formation in the light of classical models}

Three main classical models have been proposed to explain the periodicity of somite formation: the Meinhardt's model, the cell cycle model and the clock-and-wavefront model.
Meinhardt proposed that prior to the formation of each somite, presomitic cells undergo several oscillations between two alternate states corresponding to the prospective $A$ and $P$ somitic compartments (Meinhardt, 1986). As postulated, the confrontation between cells of incompatible $A$ and $P$ states would result in a physical boundary between consecutive somites, since there is no intermingling between cells from different states. Juxtaposition of these two segregated states would also lead to the formation of a physical barrier in the middle of a somite. To overcome this problem Meinhardt postulated a third oscillating state, called segment border (S), which corresponds to the somitic boundary. However, while distinct cell adhesive characteristics allowed the identification of A and P somitic compartments (Keynes and Stern, 1984), no $S$ cells have been identified so far. In addition, a study using confocal time-lapse microscopy challenges the Meinhardt's model by showing that some degree of cell intermingling between $A$ and $P$ somitic compartments does occur during somite boundary formation (Kulesa and Fraser, 2002).

In 1988, Primmett and collaborators demonstrated that a single heat-shock applied to the chick embryo gives rise to several segmentation abnormalities that are repeated along the AP axis Abbreviations used in this paper: EJM, ejemplo poner aquí ; QTR, quitar si no
hay escribir desde aquí hacia arriba.

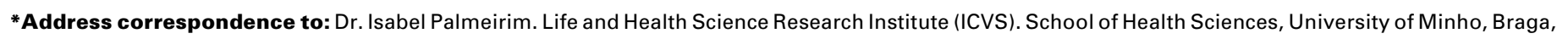
Portugal. Fax: +351-253-604-831. e-mail: ipalmeirim@ecsaude.uminho.pt 
with a regular interval of six to seven somites (Primmett et al., 1988). The time required to form six to seven somites in the chick is approximately ten hours, which corresponds to the time necessary for the completion of the cell cycle in the PSM (Primmett et al., 1989). Consequently, it was postulated that the cell cycle would function as an internal cellular clock related to the process of segmentation: cells located in the rostral PSM share some degree of cell cycle synchrony, increase their adhesive properties and thus assemble and give rise to a somite. However, no correlation between the duration of the cell cycle in PSM and the rate of somitogenesis, which takes 90 minutes in the chick embryo, has been found so far.

The clock-and-wavefront model postulated the existence of two independent phenomena accounting for the periodic somite formation (Cooke and Zeeman, 1976). On one hand, there is an intrinsic clock compelling presomitic cells to oscillate synchronously between a permissive and a non-permissive state. On the other hand and concomitantly, a wavefront travels along the embryonic axis establishing an AP gradient of differentiation. This model predicts that in order to form a somitic boundary, a group of PSM cells oscillating synchronously has to be reached by the wavefront of differentiation. Experimental data gathered so far seem to support both assumptions of the clock-and-wavefront model.

\section{The segmentation clock: the beginning of times}

In 1997, Palmeirim and collaborators provided the first molecular evidence for the existence of an intrinsic oscillator operating in the presomitic cells of chick embryos. They observed that, within groups of embryos with the exact same number of somites, the basic Helix-Loop-Helix (bHLH) transcription repressor hairy1 displayed remarkably different patterns of expression in the PSM. The authors have also demonstrated that this dynamic expression is reiterated every 90 minutes, corresponding exactly to the time required to form a pair of somites. Moreover, these mRNA oscillations were shown to be an autonomous property of PSM cells and neither a consequence of cell migration nor dependent on a diffused signal within the PSM. This pioneer study has demonstrated that presomitic cells undergo several periodic oscillations of the hairy1 gene expression before they incorporate a somite, conceptually describing a caudal wave that progresses anteriorly and stabilises in a narrow stripe in the rostral PSM (Palmeirim et al., 1997).

After the discovery of the hairy1 gene in the chick embryo, many other genes have also been reported to have a cyclic expression at the level of the PSM, suggesting that the segmentation clock involves a complex genetic network. It is now clear that the molecular mechanism underlying somitogenesis is highly conserved among vertebrates, since periodic gene transcription has also been described in mouse, zebrafish, frog and medaka. The majority of the cycling genes code for Hairy/Enhancer-of-Split (Hes) family targets of the Notch signalling pathway such as hairy1 and hairy2 in the chick (Palmeirim et al., 1997 and Jouve et al., 2000), hey2 both in chick and mouse (Leimeister etal., 2000), hes 1 and hes7 in mouse (Jouve et al., 2000; Bessho et al., 2001b), her1 and her7 in zebrafish (Holley et al., 2000; Oates and Ho, 2002;) esr9 in the frog (Li et al., 2003) and her7 in medaka (Elmasri et al., 2004). Other cycling genes encode a modulator of the Notch signalling pathway, lunatic fringe (/fng), in the chick and mouse, (McGrew et al., 1998; Aulehla and Johnson, 1999; Forsberg et al., 1998) and a Notch ligand, deltaC, in zebrafish (Jiang et al., 2000). Furthermore, work by Aulehla and colleagues (2003) has shown that a repressor of the Wnt signalling pathway, axin2, is also cycling in the mouse PSM (Aulehla et al., 2003) (Table 1). More recently, nkd1, a wnt antagonist, has also been shown to exhibit an oscillatory expression pattern in the mouse PSM, suggesting a reciprocal interaction of Notch and Wnt signals in the regulation of the segmentation clock (Ishikawa et al., 2004).

\section{Looking at the mutants}

The fact that the majority of the cycling genes code for components of the Notch signalling pathway suggests that it plays a role in the segmentation clock. Indeed, the analysis of notch1 (Conlon etal., 1995), delta-like1 (dll1), delta-like3 (dll3) (Hräbe de Angelis et al., 1997; Kusumi et al., 1998), lunatic fringe (Ifng) (Zhang and Gridley, 1998; Evrard et al., 1998), presenilin1 (Wong etal., 1997), rbp-jk (Oka et al., 1995), pofut1 (Shi and Stanley, 2003) and hes7 (Bessho et al., 2001b) mutants reveals a somitic phenotype. In general these defects consist of disrupted AP segment polarity, misaligned and misshapen caudal somites, while more rostral somites seem to be less affected. Although most of these mutations are lethal, the analysis of the embryos at early stages reveals defects in the organisation of the sclerotome and dermomyotome, eventually leading to severe perturbations in the axial skeleton. Thus far, both hes 1 and hes 5 are the only Notch signalling mutants without a somitic phenotype (Jouve et al., 2000; Ohtsuka et al., 1999). These results reflect a possible compensation by other cyclic hes genes such as hes7 (Bessho etal., 2001a). In zebrafish, several somite mutants have been isolated from a large-scale screening and the detailed analysis of their phenotypes shows a striking resemblance to the Notch signalling mouse mutants (Jiang et al., 1996; Van Eeden et al., 1996). In fact, it is now known that the phenotypes of the zebrafish mutants deadly seven (des), after

TABLE 1

\section{CYCLIC GENES REPORTED IN VERTEBRATE SPECIES}

\begin{tabular}{|c|c|c|c|c|}
\hline Chick & Mouse & Zebrafish & Frog & Medaka \\
\hline hairy1 (Palmeirim et al., 1997) & hes1 (Jouve et al., 2000) & her1 (Holley et al., 2000) & esr9(Li et al., 2003) & her7(Elmasri et al., 2004) \\
\hline hairy2 (Jouve et al., 2000) & hes7(Bessho et al., 2001b) & her7(Oates et al., 2002) & & \\
\hline hey2 (Leimeister et al., 2000) & hey2 (Leimeister et al., 2000) & deltaC (Jiang et al., 2000) & & \\
\hline Iunatic fringe & lunatic fringe & & & \\
\hline (McGrew et al., 1998; & (Forsberg et al., 1998) & & & \\
\hline \multirow[t]{2}{*}{ Aulehla and Johnson, 1999) } & axin2 (Aulehla et al., 2003) & & & \\
\hline & ndk1 (Ishikawa et al., 2004) & & & \\
\hline
\end{tabular}


eight (aei) and mind bomb (mib) are due to null mutations in notch 1, deltaD and in an ubiquitin ligase that binds Delta, respectively (Holley et al., 2002; Holley et al., 2000; Itoh et al., 2003). Injection of morpholinos targeted for these genes recapitulates the phenotype of each of these zebrafish mutants (Holley et al., 2002; Itoh et al., 2003). Although there are no zebrafish mutants for the deltaC, her1, her7 and suppressor of hairless $(s u(h))$ genes, morpholino knockdown experiments have revealed that, in the absence of the proteins coded by these genes, the embryos exhibit a somitic phenotype (Holley et al., 2002; Henry et al., 2002; Oates and Ho, 2002; Gajweski et al., 2003; Sieger et al., 2003). More recently, it has also been described that the zebrafish Her6 is an output of the Notch signalling pathway that, together with Her4, is required for maintaining the synchronization of cyclic gene expression within PSM (Pasini et al., 2004). Similarly, cyclic gene expression in the PSM is lost by reducing the receptor protein tyrosine phosphstase $\psi($ RPTP $\psi$ ) using morpholino antisense oligonucleotides, suggesting a requirement for RPTP $\psi$ in the control of the clock upstream of, or in parallel with, Delta/Notch signalling (Aerne and Ish-Horowicz, 2004) (Table 2).

Despite the somitic defects observed in the mouse and zebrafish mutants, the sclerotome and dermomyotome present a more or less organised segmental pattern, indicating that a basic metameric pattern is accomplished in the somitic derivatives. It seems that the Notch signalling pathway is important to coordinate the periodicity of somite formation and to specify somitic AP polarity, although its downregulation is not sufficient to abolish overall segmentation. This could be due to the fact that Notch activation is not the only determinant responsible for the formation of segments or because there is a certain degree of redundancy between Notch signalling components.

Phenotypic analysis of Notch signalling mutants strongly suggested that the defects observed could be due to a disruption in molecular segmentation and, therefore, the expression pattern of the cycling genes was studied in these mutants.

The expression of /fng is downregulated in $d / 1 /$, dl/3, pofut 1 and $r b p$-jk mutant mice but it is only slightly reduced in the notch1 mutant (Barrantes et al. 1999; Shi and Stanley, 2003). On the contrary, the cyclic behaviour of /fng is not affected in hes1 knockout mice (Jouve et al., 2000). In hes7 null mice /fng transcription is constitutively upregulated in all presomitic cells (Bessho et al., 2001b). The hes1 gene expression is severely downregulated in dII1, dll3 and hes 7 homozygous null embryos (Jouve et al., 2000; Dunwoodie et al., 2002; Bessho et al., 2001b). Moreover, the transcription of hey2 is also downregulated in the PSM of hes7 knockout mice (Bessho et al., 2001b). Additionally, the transcription of hes 7 is constitutively upregulated in hes7 mutants, as demonstrated by the expression of intronic probes in the PSM (Bessho et al., 2003).

In zebrafish, the cyclic expression of her1, her7 and deltaC is impaired in the aei (DeltaD), des (Notch1) and mib (Ubiquitin ligase) mutants and in the $s u(h)$ morpholino-knockdown experiments (Holley etal., 2000; Holley et al., 2002; Oates and Ho, 2002; Jiang et al., 2000; Sieger et al., 2003). Additionally, her1 is impaired in deltaC morpholino injected embryos (Holley et al., 2002). The inhibition of Her1 function in the PSM leads a loss of the cyclic expression of both her1 and deltaC. In this knockdown experiment her7 expression is decreased but its cyclic behaviour is maintained (Holley et al., 2002; Oates and Ho, 2002). A decrease in Her7 function disrupts the dynamic expression of deltaC, her1 and her7 (Oates and Ho, 2002).

Overall, these studies show that the oscillations of the cycling genes are in fact disturbed in Notch signalling mutants, reaffirming the function of the Notch pathway in driving the segmentation clock and showing that this role is conserved among vertebrates. Jiang and colleagues (2000) observed that while in normal development PSM cells oscillate synchronously, in Notch signalling mutants they drift out of synchrony eventually leading to defective somitogenesis. The authors show that in Notch signalling zebrafish mutants, the expression pattern of deltaC is normal at first, but becomes desynchronised, which could account for the sparing of the first somites in these mutants. Thus, it was proposed that the essential function of the Notch signalling pathway is to maintain the oscillations synchronised in adjacent PSM cells (Jiang etal., 2000).

\section{Dissecting clock promoters}

As discussed above there are several PSM genes that show a cyclic expression pattern, however the mechanism that generates this pattern is not completely understood. In the mouse, it was shown that the cyclic expression of Ifng in the PSM is controlled at the level of transcription by periodic activation of its promoter (Morales et al., 2002). Analysis of the Ifng promoter by successive deletions of the 5'UTR sequence led to the identification of a cis regulatory region that is able to recapitulate the cyclic expression of this gene. A human equivalent region also drives the cyclic expression of a reporter gene in the mouse PSM (Cole et al., 2002; Morales et al., 2002). Comparison of both human and mouse cis regulatory regions disclosed an evolutionary conserved 110 kilobase fragment that is a strong candidate to regulate the periodic gene

TABLE 2

\section{LOSS OF FUNCTION OF NOTCH SIGNALLING PATHWAY COMPONENTS INVOLVED IN SOMITOGENESIS}

\begin{tabular}{|c|c|}
\hline Mouse mutants & Zebrafish mutants \\
\hline With a somitic phenotype & notch1 - deadly seven (des) (Holley et al., 2002) \\
\hline hes7(Bessho et al., 2001b) & deltaD - after eight (aei) (Holley et al., 2000) \\
\hline notch1 (Conlon et al., 1995) & ubiquitin ligase - mind bomb (mib) (Itoh et al., 2003) \\
\hline \multicolumn{2}{|l|}{ rbp-jk (Oka et al., 1995) } \\
\hline presenilin1 (Wong et al., 1997) & Zebrafish morphants \\
\hline delta-like1 (Hräbe de Angelis et al., 1997; & herfmo (Holley et al., 2002; Henry et al., 2002; \\
\hline Cordes et al., 2004) & Oates and Ho, 2002; Gajewski et al., 2003) \\
\hline delta-like3 (Kusumi et al., 1998) & 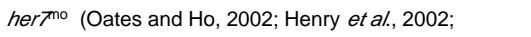 \\
\hline Iunatic fringe (Zhang and Gridley, 1998; & Gajewski et al., 2003) \\
\hline Evrard et al., 1998) & her $7^{m o}+$ her ${ }^{\text {mo }}$ (Oates and Ho, 2002; Henry et al., 2002) \\
\hline \multirow[t]{2}{*}{ pofut1 (Shi and Stanley, 2003) } & notch mo $^{\text {(Holley et al., 2002) }}$ \\
\hline & suppressor of hairless mo (Sieger-et al., 2003) \\
\hline Without a somitic phenotype & deltaC mo (Holley et al., 2002) \\
\hline hes1 (Jouve et al., 2000) & deltaD" ${ }^{\text {mo }}$ (Holley“et al., 2002) \\
\hline \multirow[t]{4}{*}{ hes5 (Ohtsuka et al., 1999) } & her4mo (Pasini et al., 2004) \\
\hline & herbmo (Pasini et al., 2004) \\
\hline & herb ${ }^{m o}+h^{2} 4^{m o}$ (Pasini et al., 2004) \\
\hline & $\operatorname{RPTP}^{\mathrm{mo}}$ (Aerne and Ish-Horowicz, 2004) \\
\hline
\end{tabular}

\footnotetext{
mo - morpholino
} 
oscillations. Further dissection of this fragment has shown that it contains two E-boxes, which are binding sites for bHLH proteins, as well as a binding site for the CBF1 (Rbp-Jk; Su(H)) transcription factor (Cole et al., 2002; Morales etal., 2002). So it seems that cyclic bHLH Notch targets may regulate the segmentation clock acting as transcriptional repressors that bind to the E-boxes in the cis -regulatory region. Indeed, Hes7 binds E-boxes and thus it was proposed to mediate the cyclic repression of Ifng (Bessho et al., 2003). Mutations in the CBF1 binding site lead to a decrease in /fng expression in the mouse PSM (Cole et al., 2002; Morales et al., 2002), which indicates that this region functions as an activator element within the promoter. In addition, these experiments also demonstrate that the expression of /fng is distinctly regulated in the anterior and the posterior part of the PSM, which is in agreement with previous work performed in the frog and the fish (Jen et al., 1999; Holley et al., 2002). Analysis of the her1 promoter in the zebrafish embryo has also demonstrated that a 5'UTR fragment is able to drive its dynamic expression in the PSM. This study also pointed to the existence of regulatory elements that distinctly control her1 expression in either the anterior or the posterior PSM (Gajewski et al., 2003). A complex interaction between repressor and activator clock elements in the promoter seems to be a general requirement for the oscillatory behaviour of segmentation genes.

\section{Unveiling the clock mechanism}

A negative feedback loop is a mechanism by which the expression of a gene is repressed by its own protein product. It has been suggested by several authors that the mechanism that drives the oscillations of the segmentation genes relies indeed on feedback inhibition.

The first direct evidence for the molecular mechanism that generates the oscillatory behaviour of the cyclic genes was presented in a study performed in cell culture (Hirata et al., 2002). The authors demonstrated that not only hes 1 mRNA, but also Hes 1 protein, undergo oscillations of expression with the same periodicity as somite formation. These oscillations are produced by a negative feedback loop in which Hes1 protein periodically represses its own transcription. This study suggested that a similar mechanism could be responsible for the transcriptional oscillations generated by the segmentation clock (Hirata et al., 2002).

Recently, it was shown that in the mouse embryo both hes7 mRNA and Hes7 protein oscillate in the PSM (Bessho et al., 2003). Hes7 protein localisation domains do not overlap with the regions where hes $7 \mathrm{mRNA}$ is expressed. Moreover, transcription of hes 7 is constitutively activated in the absence of Hes7 protein and downregulated following stabilization of Hes7 protein. Therefore, Hes7 oscillations in the PSM rely on a negative autoregulatory loop (Bessho et al., 2003). Accordingly, Hes7 protein instability was shown to be crucial for cyclic gene expression (Hirata et al., 2004). Also in the mouse embryo, it was shown that hes1 mRNA oscillations are blocked in the absence of a functional Hes 1 protein, suggesting that this protein might regulate its own promoter (Hirata et al., 2002). In zebrafish, the cyclic genes her1 and her7 seem to negatively regulate their own expression, although there is no data regarding their protein expression in the PSM (Holley et al., 2002; Oates and Ho, 2002).
Another negative feedback loop involving the periodic production of Lfng protein was described in the chick PSM (Dale et al., 2003). In addition to /fng mRNA, Lfng protein cycles with the same periodicity as somite formation. Furthermore, overexpression of Ifng in the chick PSM impairs the cyclic expression of the Notch downstream targets, hairy1, hairy2 and endogenous /fng. Since Lfng is a modulator of Notch activity, it seems that the oscillations of segmentation genes are due to periodic inhibition of Notch activation (Dale et al., 2003). Studies performed in zebrafish and mouse revealed that the function of Lfng might be different from the one in the chick. In zebrafish, Ifng mRNA does not oscillate in the PSM (Prince etal., 2001; Leve etal., 2001) and it seems that the periodic activation of Notch is undertaken by the cyclic gene deltaC (Jiang et al., 2000). In contrast, Ifng oscillates in the mouse PSM (Forsberg et al., 1998), although its constitutive expression does not abolish cyclic expression of endogenous /fng (Serth et al., 2003). This implies that the activity of Notch alone cannot be the only determinant of cyclic gene expression in the mouse embryo.

An interesting finding that might explain the Lfng results in the mouse is the role recently attributed to the Wnt signalling pathway as a regulator of the clock by acting upstream of the Notch pathway (Aulehla etal., 2003). It was shown that axin2, a negative regulator of the Wnt pathway, is expressed in the PSM in a cyclic fashion. In the vestigial tail mutant mouse, which is a hypomorphic mutant of wnt3a, there are caudal segmentation defects and, interestingly, axin2 is not expressed. Thus, a negative feedback loop was proposed in which Wnt3a induces axin2 expression and then Axin2 negatively modulates Wnt signalling. Since axin2 mRNA oscillates alternately with Ifng mRNA, it was suggested that Wnt and Notch pathways interact antagonistically through the binding of dishevelled to the Notch intercellular domain (Aulehla et al., 2003). Recently, it was shown that the Wnt-responsive transcription factor Lef1 binds to several sites in the dll1 promoter and enhancer regions and regulates its activity in the mouse PSM. This finding establishes a molecular link between the Wnt and the Notch pathways during somitogenesis (Galceran et al., 2004). So far, the involvement of Wnt signalling in the regulation of periodicity of somite formation has not been reported in other vertebrate embryos.

It is possible to consider the existence of three types of negative feedback loops by incorporating data from zebrafish, chick and mouse, although the possible interactions between these loops are still not understood: 1) a direct feedback loop that generates the cyclic expression of Hairy/ Enhancer-of-Split family of bHLH repressors (Her1 and Her7 in zebrafish and Hes1 and Hes7 in the mouse); 2) an indirect feedback loop that establishes periodic activation of Notch signalling (DeltaC in zebrafish and Lfng in the chick); 3) another indirect feedback loop that promotes periodic activation of Wnt signalling (Axin2 in the mouse) (Fig. 1).

It has been suggested that a negative feedback loop in which the expression of a gene is repressed by its own protein product would be insufficient to generate/maintain sustained oscillations (Hirata et al., 2002). However, two mathematical models based on the experimental data from zebrafish and cell culture studies show that mRNA and protein oscillations can be produced if transcriptional and translational delays are taken into account (Lewis, 2003; Monk, 2003). Nevertheless, delayed feedback will only set up the pace of oscillations if the mRNA and protein half- 
lives are effectively small in relation to the delay. Surprisingly, these mathematical models reveal that delay-driven oscillations are very resistant to parameter changes (Lewis, 2003; Monk, 2003). Simulating a reduction in the rate of protein synthesis revealed no effect on the oscillation period (Lewis, 2003), which could explain the occurrence of hairy1 oscillations in the chick PSM after cycloheximide treatment (Palmeirim et al., 1997). Moreover, a simulation where Notch signalling is impaired shows a progressive failure in the regularity of the oscillations which, in agreement with the desynchronization theory, could explain the mild defects in the first somites of zebrafish and mouse Notch mutants (Lewis, 2003; Jiang et al., 2000).

\section{The wavefront: a partner of the clock}

The clock-and-wavefront model proposes an explanation for the temporal and spatial regulation of somitogenesis. It predicts the existence of an intrinsic oscillator operating in parallel with a wavefront of differentiation, whose progression rate determines the correct positioning of somitic boundaries (Cooke and Zeeman, 1976). As previously discussed, the molecular evidence for the oscillator was provided by the cyclic expression of a number of genes, whereas the wavefront position seems to be regulated by Fgf and Wnt signalling (Dubrulle et al., 2001; Sawada et al., 2001; Aulehla et al., 2003), by retinoic acid (RA) signalling and possibly by an unknown pathway involving the T-box gene, tbx24 (Diez del Corral et al., 2003; Nikaido et al., 2002).

In the chick, fgfo defines a decreasing caudal to rostral gradient of expression in the two posterior thirds of the PSM (Dubrulle et al., 2001). AP inversion experiments of PSM tissue demonstrated that AP somitic compartments are already determined in the anterior third of the PSM, in contrast to the caudal two thirds of this tissue where segment polarity is still undetermined (Dubrulle et al., 2001). The transition between these two regions occurs at the level of the so-called determination front that progressively regresses as a consequence of embryo elongation and seems to correspond to the anterior limit of the $f g f 8$ gradient of expression. Either inhibiting or overexpressing Fgf8 at the level of the determination front alters the position of somitic boundaries, inducing the formation of larger or smaller somites, respectively. It seems that Fgf8 maintains posterior PSM cells in an immature state, thus negatively regulating the wavefront of differentiation in the chick embryo. Caudal to the determination front, the axial identity of PSM cells is also undetermined, since Fgf8 overexpression can induce an anterior shift of hoxB9 and hoxA10 expression domains (Dubrulle et al., 2001). Additionally it was proposed that an interaction between the segmentation clock and the hox genes would establish the correct coordination between sequential segment formation and AP specification (Zakany etal., 2001). Reinforcing this idea, transgenic mice expressing a dominant negative version of Delta1 in the PSM showed subtle changes of Hox gene expression and alterations of vertebral identity resembling homeotic transformations (Cordes et al., 2004).

The involvement of Fgf signalling in the control of the wavefront progression was also studied in zebrafish embryos (Sawada et al., 2001). Fgf/mitogen-activated protein kinase (MAPK) signalling is functioning in the posterior PSM and it maintains these cells in an immature state. Experimental manipulations of MAPK levels in the PSM also lead to a variation in somitic size, strengthening the idea that Fgf signalling determines the position of segment border formation (Sawada et al., 2001).

In the mouse, wnt3a seems to play a similar role to the one attributed to Fgf signalling in both chick and zebrafish PSM (Aulehla et al., 2003). wnt3a is strongly expressed in the tail bud and it was proposed to establish a decreasing caudal to rostral gradient of expression that regresses as the embryo elongates. Furthermore, fgf8 is downregulated in the tail bud and PSM of wnt3a hypomorphic mutants, suggesting that wnt3a acts upstream of $f g f 8$ in the regulation of the wavefront position. Since there is evidence that Fgf signalling may enhance Wnt/ $\beta$-catenin signalling, Fgf8 might act as a relay enhancer of Wnt signalling in the PSM of mouse embryos (Aulehla et al., 2003).

Previous studies have shown that presomitic tissue represses neuronal differentiation and that Fgf signalling can mimic this action (Diez del Corral et al., 2002). On the other hand, the somitic mesoderm promotes maturation events, which are correlated with the activation of RA signalling in rostral PSM and somites, as indicated by the expression of the RA-synthesizing enzyme raldh2 (Diez del Corral et al., 2002 and 2003). Furthermore, explant culture experiments using a RA agonist (TTNPB) and Vitamin A deficient (VAD) quail embryos, which lack biologically
Fig. 1. Feedback loops underlying periodic oscillations of cycling genes. In zebrafish, the periodic oscillations of her1 and her7 mRNA are generated by autoregulatory feedback loops and may be involved in deltaC periodic expression DeltaC in turn would periodically modulate Notch signalling activity. In the chick, Lfng protein indirectly represses its own expression by periodic modulation of the Notch signalling pathway. In the mouse, cyclic transcription of hes 7 is regulated by the periodic expression of its own protein. The same molecular feedback loop generates Hes 1 oscillations in different cell types. Additionally, the cyclic expression of axin2, a direct target of the Wnt pathway, regulates the Wnt signalling by a mechanism of feedback inhibition. It has been proposed that Wnt and Notch signalling pathways antagonistically interact since transcription of axin2 and Ifng oscillates out of phase in the mouse PSM.

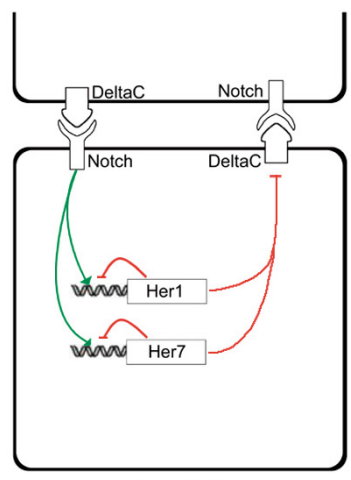

zebrafish

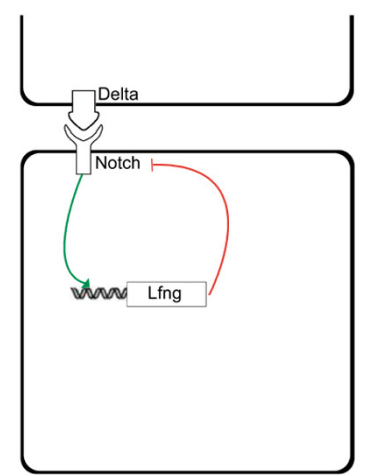

chick

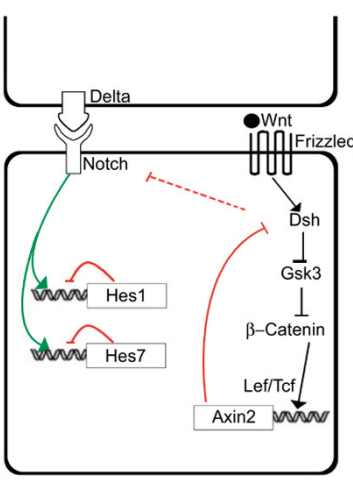

mouse 
active RA, have demonstrated that RA downregulates the expression of fgf8 in the PSM (Diez del Corral et al., 2003; Maden et al., 1996). Conversely, Fgf8 soaked beads placed in the chick PSM represses the expression of raldh2, which indicates that Fgf signalling regulates the onset of RA synthesis in presomitic tissue (Diez del Corral et al., 2003). These results show that Fgf and RA signalling pathways are mutually inhibitory and point to an important role of RA in inducing PSM cells maturation, in opposition to Fgf8. Future research will be important to reveal a possible interaction between the cycling genes (segmentation clock) and RA (wavefront) and their role in the control of somitogenesis.

The fused somites (fss) zebrafish mutant lacks all somitic boundaries and this phenotype is the result of a mutation in the tbx24 gene (Van Eeden et al., 1996; Nikaido et al., 2002). This suggests the involvement of tbx24 in the formation of somitic boundaries. Although tbx24 is expressed in anterior and intermediate PSM, its function seems to be restricted to the rostral PSM. In fact, in fss mutants segmentation genes specifically expressed in the anterior PSM are downregulated and the anterior stripe of the her1 cyclic gene is lost, whereas its expression appears to be normal in the posterior PSM. These data suggest that $t b \times 24$ plays a role in the maturation process of anterior PSM cells and that it might be independent of the molecular clock.

Fgf and Wnt signalling pathways seem to control the positioning of the wavefront of differentiation (Dubrulle et al., 2001; Sawada et al., 2001; Aulehla et al., 2003). Since the formation of somitic boundaries is such a finely tuned process it is conceivable that a signal in the anterior PSM controls the precise site of the determination front. This signal could work in combination with the Fgf and Wnt posterior gradients that maintain cells in an immature state. As discussed above, both RA and tbx24 are good candidates for this signal. Since tbx24 has only been described in zebrafish, it would be interesting to look for functional homologues in other vertebrate models and to understand how the Tbox pathway interacts with Fgf and Wnt signalling pathways.

\section{The clock in two dimensions}

It is now well established that an intrinsic oscillator operates in PSM cells as it is revealed by the periodic expression of the cyclic genes. It seems that presomitic cells perceive the number of oscillations they undergo before incorporating a somite. This suggests that the segmentation clock constitutes a mechanism that provides AP positional information to these cells, determining their spatial organisation within the PSM (Palmeirim et al., 1997). In the chick, a detailed analysis performed from stage 4 to $7 \mathrm{HH}$ (Hamburguer and Hamilton, 1951) showed that the cycling genes are expressed in the prospective somitic territory (Jouve et al., 2002). This implies that presomitic cells are provided with their future AP positional information well before the first somite is formed.

In six somite stage chick embryos (stage 9- $\mathrm{HH}$ ) a dynamic pattern of the cycling genes is also evident at the level of the presumptive presomitic territory, defining in this region an AP gradient of expression. A detailed quail-chick chimera fate map has revealed an anterior region located within this prospective territory that specifically gives rise to the medial part of the PSM and somites (Freitas et al., 2001). Therefore, the AP gradient of expression in the prospective PSM territory describes a wave spreading throughout the future medial/lateral (ML) presomitic axis. Accordingly, a more careful analysis of expression pattern of the cycling genes at the level of the PSM unveils a ML asynchrony that is evidenced by oblique stripes of gene expression corresponding to a transition between two horizontal stripes (see supplemental data at:http://www.ijdb.ehu.es/ijdb200549023/49023esm317.mov). Thus, the segmentation clock is providing cellular positional information in at least two dimensions: not only along the AP but also along the ML presomitic axis (Freitas et al., 2001).

\section{Final remarks}

The development of a living organism is highly regulated in space and time. The only biological clock known to operate during embryonic development is the segmentation clock underlying the highly coordinated process of somite formation in vertebrates. However, the nature of the signal that triggers the molecular clock, early in development, remains to be determined. The segmentation clock is currently perceived as a cross talk between Notch and Wnt signalling cascades, consisting of complex regulatory feedback loops that ultimately generate periodic gene oscillations in presomitic cells. The cyclic transcription will only be translated into visible periodic gene expression patterns if both 1) the halflife of the mRNA is shorter than its transcription cycle and 2) a group of neighbouring cells is synchronous. It is possible that other genes undergoing cyclic transcription are not detected and so, their existence cannot be ruled out.

Recently, it was shown that the involvement of the Notch signalling pathway in the process of segmentation is not exclusive to vertebrates since it has been shown to be essential for the formation of segments in spiders (Stollewerk et al., 2003). Such a finding suggests that a common ancestor of both vertebrates and arthropods might have used the same molecular mechanism for segmentation. Therefore, the fact that Drosophila does not use the Notch signalling pathway to make segments suggests that arthropods that generate segments simultaneously might have lost this ancestral segmentation strategy during evolution. It remains to be clarified whether the Notch signalling pathway is used by all sequentially segmented arthropods as well as whether a clock-like mechanism drives the cyclic transcription of Notch targets in these organisms.

It is now evident that a conserved clock mechanism dictates the timing of segment formation. At this point, an interesting question that arises is whether this clock operates in tissues other than presomitic mesoderm. As a matter of fact, an in vitro study has shown that several mouse cell lines express hes 1 mRNA and protein in a cyclic fashion. This, points to the possibility that different types of cells might measure time using a similar clock mechanism (Hirata et al., 2002). Work from our group has provided evidence for cyclic hairy2 expression in the chick limb bud, indicating that the clock mechanism is also controlling limb outgrowth (Pascoal et al., in preparation). It is therefore tempting to postulate that the rearrangement of cells into tissues and organs requires different coordinated events controlled by a common mechanism that counts time.

\footnotetext{
Acknowledgements

We thank Sólveig Thorsteinsdóttir, Raquel Andrade, Ana Tavares, Will Wood and Joaquín Rodriguez-León for helpful comments on the
} 
manuscript. Animation (supplemental data) was produced by Spirituc (www.spirituc.com). Financialsupportwas provided by Instituto Gulbenkian de Ciência and by Fundação para a Ciência e a Tecnologia (F.C.T.) project no. 34599. C.F. is supported by F.C.T. PRAXIS/XXI/BD/21583/ 99; S.R. is supported by F.C.T. project no. 34599; L.S. is supported by F.C.T. SFRH/BPD/6755/2001.

\section{References}

AERNE B. and ISH-HOROWICZ D. (2004). Receptor tyrosine phosphatase psi is required for Delta/Notch signalling and cyclic gene expression in the presomitic mesoderm. Development 131: 3391-9.

AULEHLA, A. and JOHNSON, R.L. (1999). Dynamic expression of lunatic fringe suggests a link between notch signalling and an autonomous cellular oscillator driving somite segmentation. Dev Biol. 207: 49-61.

AULEHLA, A., WEHRLE, C., BRAND-SABERI, B., KEMLER, R., GOSSLER, A., KANZLER, B. and HERRMANN, B.G. (2003). Wnt3a plays a major role in the segmentation clock controlling somitogenesis. Dev. Cell 4: 395-406.

BARRANTES, I.B., ELIA, A.J., WUNSCH, K., HRÄBE DE ANGELIS, M., MAK, T.W., ROSSANT, J., CONLON, R.A., GOSSLER, A. and DE LA POMPA, J.L. (1999). Interaction between Notch signalling and Lunatic fringe during somite boundary formation in the mouse. Curr Biol. 9: 470-480.

BESSHO, Y., MIYOSHI, G., SAKATA, R. and KAGEYAMA, R. (2001a). Hes7: a bHLH-type repressor gene regulated by Notch and expressed in the presomitic mesoderm. Genes Cells. 6: 175-85.

BESSHO, Y., SAKATA, R., KOMATSU, S., SHIOTA, K., YAMADA, S., YAMADA, S. and KAGEYAMA, R. (2001b). Dynamic expression and essential functions of Hes7 in somite segmentation. Genes and Dev. 15: 2642-2647.

BESSHO, Y., HIRATA, H., MASAMIZU, Y. and KAGEYAMA, R. (2003). Periodic repression by the bHLH factor Hes7 is an essential mechanism for the somite segmentation clock. Genes Dev. 17: 1451-1456.

COLE, S.E., LEVORSE, J.M., TILGHMAN, S.M. and VOGT, T.F. (2002). Clock regulatory elements control cyclic expression of /unatic fringe during somitogenesis. Dev. Cell 3: 75-84.

CONLON, R.A., REAUME, A.G. and ROSSANT, J. (1995). Notch1 is required for the co-ordinate segmentation of somites. Development 121: 1533-1545.

COOKE, J. and ZEEMAN, E.C. (1976). A clock-and-wavefront model for control of the number of repeated structures during animal morphogenesis. J. Theor. Biol. 58 : 455-476.

CORDES R., SCHUSTER-GOSSLER K., SERTH K. and GOSSLER A. (2004). Specification of vertebral identity is coupled to Notch signalling and the segmentation clock. Development 131:1221-33.

DALE, J.K., MAROTO, M., DEQUEANT, M.L., MALAPERT, P., MCGREW, M. and POURQUIÉ, O. (2003). Periodic notch inhibition by lunatic fringe underlies the chick segmentation clock. Nature 421: 275-278.

DIEZ DEL CORRAL, R., BREITKREUZ, D.N. and STOREY, K.G. (2002). Onset of neuronal differentiation is regulated by paraxial mesoderm and requires attenuation of FGF signalling. Development 129: 1681-91.

DIEZ DEL CORRAL, R., OLIVERA-MARTINEZ, I., GORIELY, A., GALE, E., MADEN, M. and STOREY, K. (2003) Opposing FGF and retinoid pathways control ventral neural pattern, neuronal differentiation and segmentation during body axis extension. Neuron. 40:65-79.

DUBRULLE, J., MCGREW, M.J. and POURQUIÉ, P. (2001). FGF signalling controls somite boundary position and regulates segmentation clock control of spatiotemporal Hox gene activation. Cell 106: 219-232.

DUNWOODIE, S.L., CLEMENTS, M., SPARROW, D.B., SA, X., CONLON, R.A. and BEDDINGTON, R.S. (2002). Axial skeletal defects caused by mutation in the spondylocostal dysplasia/pudgy gene DII3 are associated with disruption of the segmentation clock within the presomitic mesoderm. Development 129: 1795-806.

ELMASRI H., LIEDTKE D., LUCKING G., VOLFF J.N., GESSLER M. and WINKLER C. (2004). her7 and hey1, but not lunatic fringe show dynamic expression during somitogenesis in medaka (Oryzias latipes). Gene Expr Patterns. 4: 553-9.

EVRARD, Y.A., LUN, Y., AULEHLA, A., GAN, L. and JOHNSON, R.L. (1998). lunatic fringe is an essential mediator of somite segmentation and patterning. Nature 394: 377-381.
FORSBERG, H., CROZET, F. and BROWN, N.A. (1998). Waves of mouse Lunatic fringe expression, in four-hour cycles at two-hour intervals, precede somite boundary formation. Curr Biol. 8: 1027-1030.

FREITAS, C., RODRIGUES, S., CHARRIER, J.B., TEILLET, M.A. and PALMEIRIM, I. (2001). Evidence for medial/lateral specification and positional information within the presomitic mesoderm. Development 128: 5139-5147.

GAJEWSKI, M., SIEGER, D., ALT, B., LEVE, C., HANS, S., WOLFF, C., ROHR, K.B. and TAUTZ, D. (2003). Anterior and posterior waves of cyclic her1 gene expression are differentially regulated in the presomitic mesoderm of zebrafish. Deve/opment 130: 4269-78.

GALCERAN, J., SUSTMANN, C., HSU, S.-C., FOLBERTH, S. and GROSSCHEDL, R. (2004). LEF1-mediated regulation of Delta-like1 links Wnt and Notch signaling in somitogenesis. Genes \& Dev. 18: 2718-2723.

GOSSLER, A. and HRÄBE DE ANGELIS, M. (1998). Somitogenesis. Curr Top Dev Biol. 38: 225-287.

HAMBURGER, V. and HAMILTON, H.L. (1951). A series of normal stages in the development of the chick embryo. J. Morphol. 88: 49-92.

HENRY, C.A., URBAN, M.K., DILL, K.K., MERLIE, J.P., PAGE, M.F., KIMMEL, C.B AND AMACHER, S.L. (2002). Two hairy/Enhancer of split-related zebrafish genes, her1 and her7, function together to refine alternating somite boundaries. Development 129: 3693-3704.

HIRATA, H., YOSHIURA, S., OHTSUKA, T., BESSHO, Y., HARADA, T., YOSHIKAWA K. and KAGEYAMA, R. (2002). Oscillatory Expression of the bHLH Factor Hes 1 Regulated by a Negative Feedback Loop. Science. 298: 840-843.

HIRATA H., BESSHO Y., KOKUBU H., MASAMIZU Y., YAMADA S., LEWIS J. and KAGEYAMA R. (2004). Instability of Hes7 protein is crucial for the somite segmentation clock. Nat Genet. 36: 750-4.

HOLLEY, S.A., GEISLER, R. and NUSSLEIN-VOLHARD, C. (2000). Control of her1 expression during zebrafish somitogenesis by a delta-dependent oscillator and an independent wave-front activity. Genes Dev. 14: 1678-1690.

HOLLEY, S.A., JULICH, D., RAUCH, G.J., GEISLER, R. and NUSSLEIN-VOLHARD, C. (2002). her1 and the notch pathway function within the oscillator mechanism that regulates zebrafish somitogenesis. Development 129(5): 1175-1183.

HRÄBE DE ANGELIS, M., MCINTYRE, J. 2ND AND GOSSLER, A. (1997). Maintenance of somite borders in mice requires the Delta homologue DII1. Nature 386 717-721.

ISHIKAWA, A., KITAJIMA, S., TAKAHASHI, Y., KOKUBO, H., KANNO, J., INOUE, T. and SAGA, Y. Mouse Nkd1, a Wnt antagonist, exhibits oscillatory gene expression in the PSM under the control of Notch signalling. Mech. Dev. 121: 1443-1453.

ITOH, M., KIM, C.H., PALARDY, G., ODA, T., JIANG, Y.J., MAUST, D., YEO, S.Y., LORICK, K., WRIGHT, G.J., ARIZA-MCNAUGHTON, L., WEISSMAN, A.M., LEWIS, J., CHANDRASEKHARAPPA, S.C. and CHITNIS, A.B. (2003). Mind Bomb is an ubiquitin ligase that is essential for efficient activation of Notch signalling by Delta. Dev. Cell 4: 67-82.

JEN, W.C., GAWANTKA, V., POLLET, N., NIEHRS, C. and KINTNER, C. (1999). Periodic repression of Notch pathway genes governs the segmentation of Xenopus embryos. Genes Dev. 13: 1486-1499.

JIANG, Y.J., BRAND, M., HEISENBERG, C.P.,BEUCHLE, D., FURUTANI-SEIKI, M., KELSH, R.N., WARGA, R.M., GRANATO, M., HAFFTER, P., HAMMERSCHMIDT, M., KANE, D.A., MULLINS, M.C., ODENTHAL, J., VAN EEDEN, F.J. and NUSSLEIN-VOLHARD, C. (1996). Mutations affecting neurogenesis and brain morphology in the zebrafish, Danio rerio. Development 123: 205-216.

JIANG, Y.J., AERNE, B.L., SMITHERS, L., HADDON, C., ISH-HOROWICZ, D. and LEWIS, J. (2000). Notch signalling and the synchronization of the somite segmentation clock. Nature 408: 475-479.

JOUVE, C., PALMEIRIM, I., HENRIQUE, D., JOHANNES, B., GOSSLER, A., ISHHOROWICZ, D. and POURQUIÉ, O. (2000). Notch signalling is required to maintain the vertebrate segmentation clock. Development 127: 1421-1429.

JOUVE, C., IIMURA, T. and POURQUIÉ, O. (2002). Onset of the segmentation clock in the chick embryo: evidence for oscillations in the somite precursors in the primitive streak. Development 129: 1107-1117.

KEYNES, R.J. and STERN, C.D. (1984). Segmentation in the vertebrate nervous system. Nature 310: 786-9.

KULESA, P.M. and FRASER, S. (2002). Cell dynamics during somite boundary formation revealed by time-lapse analysis. Science. 298: 991-995. 
KUSUMI, K., SUN, E.S., KERREBROCK, A.W., BRONSON, R.T., CHI, D.C., BULOTSKY, M.S., SPENCER, J.B., BIRREN, B.W., FRANKEL, W.N. and LANDER, E.S. (1998). The mouse pudgy mutation disrupts Delta homologue DII3 and initiation of early somite boundaries. Nat Genet. 19: 274-278.

LEIMEISTER, C., DALE, J.K., FISCHER, A., KLAMT, B., HRÄBE DE ANGELIS, M., RADTKE, F., MCGREW, M. J., POURQUIÉ, O. and GESSLER, M. (2000). Oscillating expression of c-Hey2 in the presomitic mesoderm suggests that the segmentation clock may use combinatorial signalling through multiple interacting bHLH factors. Dev. Biol. 227: 91-103.

LEVE, C., GAJEWSKI, M., ROHR, K.B. and TAUTZ, D. (2001). Homologues of c-hairy1 (her9) and lunatic fringe in zebrafish are expressed in the developing central nervous system, but not in the presomitic mesoderm. Dev Genes Evol. 211: 493500.

LEWIS, J. (2003). Autoinhibiton with transcriptional delay: a simple mechanism for the zebrafish somitogenesis oscillator. Curr. Biol. 13: 1398-1408.

LI, Y., FENGER, U., NIEHRS, C. and POLLET, N. (2003). Cyclic expression of esr9 gene in Xenopus presomitic mesoderm. Differentiation 71: 83-89.

MADEN, M., GALE, E., KOSTETSKII, I. and ZILE, M. (1996). Vitamin A-deficient quail embryos have half a hindbrain and other neural defects. Curr Biol. 6: 417-26.

MCGREW, M.J., DALE, J.K., FRABOULET, S. AND POURQUIÉ, O. (1998). The lunatic fringe gene is a target of the molecular clock linked to somite segmentation in avian embryos. Curr. Biol. 8: 979-982.

MEINHARDT, H. (1986). Models of segmentation. In Somites in developing embryos (R. Bellairs, D.A. Ede and J.W. Lash eds). Plenum Press, New York. pp. $179-189$.

MONK, N.A.M. (2003). Oscillatory Expression of Hes1, p53 and NF-small kappa, GreekB Driven by Transcriptional Time Delays. Curr. Biol. 13: 1409-1413.

MORALES, A.V., YASUDA, Y. and ISH-HOROWICZ D. (2002). Periodic Lunatic fringe expression is controlled during segmentation by a cyclic transcriptional enhancer responsive to notch signalling. Dev Cel/ 3: 63-74.

NIKAIDO, M., KAWAKAMI, A., SAWADA, A., FURUTANI-SEIKI, M., TAKEDA, H. and ARAKI, K. (2002). Tbx24, encoding a T-box protein, is mutated in the zebrafish somite-segmentation mutant fused somites. Nat Genet. 31: 195-199.

OATES, A.C. and HO, R.K. (2002) Hairy/E(spl)-related (Her) genes are central components of the segmentation oscillator and display redundancy with the Delta/ Notch signalling pathway in the formation of anterior segmental boundaries in the zebrafish. Development 129(12): 2929-46.

OTSUKA, T., ISHIBASHI, M., GRADWOHL, G., NAKANISHI, S., GUILLEMOT, F. and KAGEYAMA, R. (1999). Hes 1 and Hes5 as Notch effectors in mammalian neuronal differentiation. EMBO J. 18: 2196-2207.

OKA, C., NAKANO, T., WAKEHAM, A., DE LA POMPA, J.L., MORI, C., SAKAI, T., OKAZAKI, S., KAWAICHI, M., SHIOTA, K., MAK, T.W. and HONJO, T. (1995).
Disruption of the mouse RBP-J kappa gene results in early embryonic death. Development 121: 3291-3301.

PALMEIRIM, I., HENRIQUE, D., ISH-HOROWICZ, D. and POURQUIÉ, O. (1997) Avian hairy gene expression identifies a molecular clock linked to vertebrate segmentation and somitogenesis. Cel/ 91: 639-648.

PASINI A., JIANG Y.J. and WILKINSON D.G. (2004). Two zebrafish Notch-dependent hairy/Enhancer-of-split-related genes, her6 and her4, are required to maintain the coordination of cyclic gene expression in the presomitic mesoderm. Development 131:1529-41.

PRIMMETT, D.R., STERN, C.D. and KEYNES, R.J. (1988). Heat shock causes repeated segmental anomalies in the chick embryo. Development 104: 331-339.

PRIMMETT, D.R., NORRIS, W.E., CARLSON, G.J., KEYNES, R.J. and STERN, C.D (1989). Periodic segmental anomalies induced by heat shock in the chick embryo are associated with the cell cycle. Development 105: 119-30.

PRINCE, V.E., HOLLEY, S.A., BALLY-CUIF, L., PRABHAKARAN, B., OATES, A.C. HO, R.K. and VOGT, T.F. (2001). Zebrafish lunatic fringe demarcates segmental boundaries. Mech Dev. 105: 175-180.

SAWADA, A., SHINYA, M., JIANG, Y.J., KAWAKAMI, A., KUROIWA, A. and TAKEDA, $H$. (2001). Fgf/MAPK signalling is a crucial positional cue in somite boundary formation. Development 128: 4873-4880.

SERTH, K., SCHUSTER-GOSSLER, K., CORDES, R. and GOSSLER, A. (2003). Transcriptional oscillation of lunatic fringe is essential for somitogenesis. Genes Dev. 17: 912-925.

SHI, S. and STANLEY, P. (2003). Protein O-fucosyltransferase 1 is an essential component of Notch signalling pathways. Proc. Natl. Acad. Sci. USA.100: 52345239

SIEGER, D., TAUTZ, D. and GAJEWSKI, M. (2003). The role of Suppressor of Hairless in Notch mediated signalling during zebrafish somitogenesis. Mech. Dev. 120: 1083-1094.

STOLLEWERK, A., SCHOPPMEIER, M. and DAMEN, W.G. (2003). Involvement of Notch and Delta genes in spider segmentation. Nature 423: 863-865.

VAN EEDEN, F.J.M., HOLLEY, S.A., HAFFTER, P. and NÜSSLEIN-VOLHARD, C (1996). Zebrafish Segmentation and Pair-Rule Patterning. Dev. Gen. 23: 65-76

WONG, P.C., ZHENG, H., CHEN, H., BECHER, M.W., SIRINATHSINGHJI, D.J., TRUMBAUER, M.E., CHEN, H.Y., PRICE, D.L., VAN DER PLOEG, L.H. and SISODIA, S.S. (1997). Presenilin 1 is required for Notch1 and DIl1 expression in the paraxial mesoderm. Nature 387: 288-292.

ZAKANY, J., KMITA, M., ALARCON, P., DE LA POMPA, J.L. and DUBOULE, D. (2001). Localized and transient transcription of Hox genes suggests a link between patterning and the segmentation clock. Cell 106: 207-17.

ZHANG, N. and GRIDLEY, T. (1998). Defects in somite formation in lunatic fringedeficient mice. Nature 394: 374-377. 